\title{
Comparative study of single versus double time application of dinoprostone E2 gel on the induction of labor in term pregnancy and it's fetomaternal outcomes
}

\author{
Santosh Khajotia, Manoj Gupta*, Mool Chand Khichar, Madhuri Sharma, Kavita Choudhary
}

Department of Obstetrics and Gynecology, S.P. Medical College P.B.M. Associated Group of Hospitals, Bikaner, Rajasthan, India

Received: 10 June 2021

Accepted: 07 July 2021

Accepted: 08 July 2021

\section{*Correspondence:}

Dr. Manoj Gupta,

E-mail: mannugupta.sms@gmail.com

Copyright: (c) the author(s), publisher and licensee Medip Academy. This is an open-access article distributed under the terms of the Creative Commons Attribution Non-Commercial License, which permits unrestricted non-commercial use, distribution, and reproduction in any medium, provided the original work is properly cited.

\section{ABSTRACT}

Background: Labor is defined as a cascade of effective uterine contractions leading to progressive effacement and dilatation of cervix resulting in the expulsion of the fetus, placenta and the membranes. The aim of the study was to evaluate the effect of single time and double time application of dinoprostone E2 gel and to compare fetomaternal outcomes after single and double application of dinoprostone E2 gel and its complications.

Methods: This was a prospective observational study conducted on 200 pregnant females with a period of gestation $\geq 37$ completed weeks between $1^{\text {st }}$ January 2020 to $31^{\text {st }}$ January 2021 . Group A included females undergoing single time application of PGE2 gel and in group B, second dose applied after 6 hrs of first dose if there was no improvement in Bishop score. If necessary, oxytocin for augmentation of labor was started only $6 \mathrm{hrs}$ after the last dose.

Results: Mean age in group A was 24.38 \pm 4.37 years and in group B was 24.02 \pm 3.76 years and this difference was not found statistically significant $(\mathrm{p}>0.05)$. Majority of cases had vaginal delivery. In group A, $28 \%$ cases had LSCS delivery while in group B, $17 \%$ cases had LSCS delivery ( $p>0.05)$. There was significant increase in mean Bishop score after second dose of PGE2 gel in double application group by 3.24 assessed at 12 hours after induction. Double times application of gel resulted in a smaller number of failed inductions i.e.; 23 out of 100 cases in single application group and 7 out of 100 cases in double application group. Main maternal complication was nausea and vomiting which was $5 \%$ cases in group A and $11 \%$ cases in group B.

Conclusions: Double times application of dinoprostone gel resulted in improved Bishop score, facilitates the process of induction, increased number of successful inductions, shortened application delivery interval and decreased cesarean section rate compared to single application. There was slight increase in maternal and fetal complications with double times application.

Keywords: Dinoprostone, Induction of labour, Augmentation

\section{INTRODUCTION}

In the era of modern medicine, with the increasing awareness over the past few years, labour is often induced to decrease risk of maternal or neonatal morbidity and mortality. In case of unfavourable cervix, a successful vaginal birth is less likely. Bishop developed a standardized cervical scoring system for cervical assessment. The duration of labor is inversely correlated with the Bishop score; a score that exceeds 8 describes the patient most likely to achieve a successful vaginal birth. Bishop score of less than 6 usually require a cervical ripening method to be used before other methods. ${ }^{1,2}$ Calder et al said that ripening of cervix governs the ease and the 
success of induction of labor. ${ }^{3}$ Prins et al said that if ripening of cervix fails to occur, then delivery and labor may be prolonged and sometimes unsuccessful. ${ }^{4}$ To be successful, induction of labor must fulfil three aims. First it should result in labor namely adequate uterine contractions and progressive dilatation of cervix. Second this labor should result in vaginal delivery, as there is little purpose in bringing about labor as a mere preparation for cesarean section. Third, in viable pregnancies, these aims must be achieved with minimum discomfort and risk to both mother and fetus. Favourable predictive factors for successful induction of labor are: (a) pregnancy nearer the term or post term; (b) Bishop score $\geq 6$ is favourable; (c) positive oxytocin sensitivity test of uterus; (d) presence of fetal fibronectin (fFN) in vaginal swab (>50 ng/ml); and (e) oher factors- maternal height $>5$, normal BMI, EFW $<3 \mathrm{~kg}$.

\section{Bishop score}

Bishop score also known as pre-labor scoring system which is assessed by manual vaginal examination. ${ }^{5}$ Duration of labor is inversely correlated with the Bishop score. Cervical effacement is replaced with cervical length in modified Bishop score.

Table 1: Bishop score.

\begin{tabular}{|lllll|}
\hline Cervix & Bishop score & & & \\
& $\mathbf{0}$ & $\mathbf{1}$ & $\mathbf{2}$ & $\mathbf{3}$ \\
\hline Cervical dilation $(\mathbf{c m})$ & 0 & $1-2$ & $3-4$ & $5+$ \\
\hline Cervical length $(\mathbf{c m})$ & $>4$ & $2-4$ & $1-2$ & $<1$ \\
\hline Station of presenting part & -3 or above & -2 & $-1,0$ & $+1,+2$ \\
\hline Consistency & Firm & Medium & Soft & - \\
\hline Position & Posterior & Mid-position & Anterior & - \\
\hline
\end{tabular}

Note: Total score-13, favourable score- 6-13, unfavourable score- 1-5.

\section{METHODS}

This was a prospective study conducted in the department of Obstetrics and Gynaecology, S.P. Medical College and Associated Group of Hospitals, Bikaner, Rajasthan from $1^{\text {st }}$ January 2020 to $31^{\text {st }}$ January 2021. The study population constituted 200 pregnant females with period of gestation $\geq 37$ completed weeks admitted in the labor room in obstetrics and gynaecology department of Sardar Patel Medical College, Bikaner.

\section{Group A}

Included females undergoing single time application of dinoprostone E2 gel and were observed for next $24 \mathrm{hrs}$.

\section{Group B}

Included females undergoing double times application of the dinoprostone E2 gel where second dose given after 6 hrs of first dose administration and were observed for next 18 hrs. $^{6,7}$

\section{Application of PGE2 gel}

Under all aseptic precautions PGE2 gel containing $0.5 \mathrm{mg}$ dinoprostone pre-filled syringe instilled strictly intracervically under the direct visualization of cervix using speculum. Contents of syringe ( $3 \mathrm{~g}$ gel containing $0.5 \mathrm{mg}$ of PGE2) was administered into the cervical canal starting from the level of internal os, while slowly withdrawing the catheter. After application, patient was advised to remain recumbent for $30 \mathrm{~min}$ to avoid spillage of gel. The application was repeated after 6 hrs in group B patients if there was no improvement in Bishop score. If necessary, oxytocin for augmentation of labor was started only $6 \mathrm{hrs}$ after the last dose.

If after $24 \mathrm{hrs}$, labor not occurred then patients from both the groups considered as failed induction cases. Temperature, pulse, respiratory rate, blood pressure, uterine activity and vaginal bleeding was examined immediately after insertion, then hourly for 4-6 hrs. After delivery Apgar score was calculated, baby vitals were taken care into account if there was any distress due to meconium aspiration or any other means.

\section{Statistical analysis}

Appropriate statistical analysis was applied using Chi square test, mean $\pm \mathrm{SD}$, p value $<0.05$ was significant using SPSS version 17.0 statistical software.

\section{RESULTS}

The present study was conducted in department of obstetrics and gynaecology, S.P. Medical College and associated group of Hospitals, Bikaner, consisting of 200 patients. Cases were selected for induction of labour by taking into consideration all inclusion and exclusion criteria. Then dinoprostone gel was applied intracervically and effect on progress of labour checked by assessing improvement in Bishop score.

In this study, we divided our patients into two groups (100 patients in each group) i.e.; group A (single application group) and group B (double application group where PGE2 gel repeated after 6 hrs of first application). Mean age in group A was $24.38 \pm 4.37$ years and in group B was $24.02 \pm 3.76$ years and this difference was not found statistically significant ( $p>0.05$ ) (Table 2). Out of total 200 
cases, $68 \%$ and $59 \%$ were nulliparous and $32 \%$ and $41 \%$ were multiparous in group A and group B respectively and this difference was not found statistically significant $(\mathrm{p}>0.05)$ (Table 2).

Majority of cases had their gestational age between 37-38 weeks, where total 156 cases were found having $78 \%$ in each group $\mathrm{A}$ and $\mathrm{B}$ and this difference was found statistically insignificant ( $\mathrm{p}>0.05$ ) (Table 3 ).
Out of total 200 cases, 154 females had normal vaginal delivery and out of them, 72 females belonged to group A and 82 females belonged to group B while 45 females had cesarean section delivery and out of them 28 belonged to group $\mathrm{A}$ and 17 females belonged to group $\mathrm{B}$.

Only 1 female had instrumental delivery and she belonged to group B (Table 3).

Table 2: Distribution of cases according to the age (years).

\begin{tabular}{|c|c|c|c|c|c|c|}
\hline \multirow{2}{*}{ Characteristics } & \multicolumn{2}{|c|}{ Group A (single application) } & \multicolumn{2}{|c|}{ Group B (double application) } & \multicolumn{2}{|l|}{ Total } \\
\hline & No. of cases & $\%$ & No. of cases & $\%$ & No. of cases & $\%$ \\
\hline \multicolumn{7}{|c|}{ Age group (years) } \\
\hline$\leq 20$ & 22 & 22.0 & 21 & 21.0 & 43 & 21.5 \\
\hline $21-25$ & 44 & 44.0 & 45 & 45.0 & 89 & 44.5 \\
\hline $26-30$ & 23 & 23.0 & 27 & 27.0 & 50 & 25.0 \\
\hline $31-35$ & 9 & 9.0 & 7 & 7.0 & 16 & 8.0 \\
\hline $36-40$ & 2 & 2.0 & 0 & - & 2 & 1.0 \\
\hline Total & 100 & & 100 & & 200 & \\
\hline \multicolumn{7}{|l|}{ Parity } \\
\hline Nulliparous & 68 & 68.0 & 59 & 59.0 & 127 & 63.5 \\
\hline Multiparous & 32 & 32.0 & 41 & 41.0 & 73 & 36.5 \\
\hline \multicolumn{7}{|c|}{ Gestational age (weeks) } \\
\hline $37-38$ & 78 & 78.0 & 78 & 78.0 & 156 & 78.0 \\
\hline $39-40$ & 19 & 19.0 & 19 & 19.0 & 38 & 19.0 \\
\hline$>40$ & 3 & 3.0 & 3 & 3.0 & 6 & 3.0 \\
\hline
\end{tabular}

Table 3: Distribution of cases according to the mode of delivery.

\begin{tabular}{|llllllll|}
\hline & Group A (single application) & \multicolumn{2}{l|}{ Group B (double application) } & \multicolumn{2}{c|}{ Total } \\
Mode of delivery & No. of cases & \% & No. of cases & \% & No. of cases & \% \\
\hline Normal vaginal & 72 & 72.0 & 82 & 82.0 & 154 & 77.0 \\
\hline Instrumental vaginal & 0 & - & 1 & 1.0 & 1 & 0.5 \\
\hline C. section & 28 & 28.0 & 17 & 17.0 & 45 & 22.5 \\
\hline Total & 100 & & 100 & & 200 & \\
\hline
\end{tabular}

Note: $\chi^{2}=2.823, \mathrm{p}=0.093$.

30 females had NPOL or failed induction and out of them 23 and 7 females belonged to group A and B respectively, 10 females had meconium with fetal distress and out of them 3 and 7 females belonged to group $A$ and B respectively, 4 females had fetal distress and out of them 2 females belonged to each group, while only 1 female had placental abruption which belonged to group B (Table 4). In present study, out of total 100 females of group A, 5 females had nausea/vomiting while 1 female had PPH and all other females had no complications while in group B, out of total 100 females, 11 females had nausea/vomiting, 2 females each had hyperstimulation and PPH and 85 females had no complications (Table 5).

Apgar score at $1 \mathrm{~min}, 17$ neonates had their APGAR score $<8$ and out of them 4 and 13 belonged to group A and B respectively while 183 neonates had their Apgar score at 1 min $\geq 8$ and out of them 96 and 87 neonates belonged to group A and B respectively (Table 6).

Apgar score at 5 min, 2 neonates had their Apgar score $<8$, both belonged to group B while 198 neonates had their Apgar score at $5 \mathrm{~min} \geq 8$ and out of them 100 and 98 neonates belonged to group A and B respectively. In group A, all 4 neonates improved their Apgar score from $<8$ at 1 min to $\geq 8$ at 5 min while in group B, 11 out of 13 neonates improved their Apgar score from $<8$ at 1 minute to $\geq 8$ at 5 min (Table 6). Majority of cases $(\mathrm{N}=169)$ had their indication postdatism and out of them, 83 and 86 belonged to group A and B respectively, 22 cases had PIH and out of them 9 cases belonged to group A and 13 cases belonged to group B, 5 cases had IUGR and they all belonged to group A while 4 cases had obstetric cholestasis and out of them 3 belonged to group A and 1 belonged to group B (Figure 1). 
Table 4: Distribution of cases according to the indications of cesarean section.

\begin{tabular}{|c|c|c|c|c|c|c|}
\hline \multirow{2}{*}{$\begin{array}{l}\text { Indications of C. } \\
\text { section }\end{array}$} & \multicolumn{2}{|c|}{ Group A (single application) } & \multicolumn{2}{|c|}{ Group B (double application) } & \multicolumn{2}{|l|}{ Total } \\
\hline & No. of cases & $\%$ & No. of cases & $\%$ & No. of cases & $\%$ \\
\hline Fetal distress & 2 & 7.1 & 2 & 11.8 & 4 & 8.9 \\
\hline $\begin{array}{l}\text { Meconium+fetal } \\
\text { distress }\end{array}$ & 3 & 10.7 & 7 & 41.2 & 10 & 22.2 \\
\hline $\begin{array}{l}\text { NPOL+failed } \\
\text { induction }\end{array}$ & 23 & 82.2 & 7 & 41.2 & 30 & 66.7 \\
\hline Placental abruption & 0 & 0 & 1 & 5.8 & 1 & 2.2 \\
\hline Total & 28 & & 17 & & 45 & \\
\hline
\end{tabular}

Table 5: Distribution of cases according to the maternal complications after application of gel.

\begin{tabular}{|llllllll|}
\hline Maternal & Group A (single application) & \multicolumn{2}{ll}{ Group B (double application) } & \multicolumn{2}{l|}{ Total } \\
complications & No. of cases & \% & No. of cases & \% & No. of cases & \% \\
\hline Nausea/vomiting & 5 & 5 & 11 & 11 & 16 & 8 \\
\hline Hyperstimulation & 0 & 0 & 2 & 2 & 2 & 1 \\
\hline PPH & 1 & 1 & 2 & 85 & 179 & 89.5 \\
\hline None & 94 & 94 & 85 & & 200 & \\
\hline Total & 100 & & 100 & & & 1.5 \\
\hline
\end{tabular}

Table 6: Distribution of cases according to the neonatal outcome.

\begin{tabular}{|c|c|c|c|c|c|c|c|}
\hline \multirow{2}{*}{\multicolumn{2}{|c|}{ Apgar score }} & \multicolumn{2}{|c|}{ Group A (single application) } & \multicolumn{2}{|c|}{ Group B (double application) } & \multicolumn{2}{|l|}{ Total } \\
\hline & & No. of cases & $\%$ & No. of cases & $\%$ & No. of cases & $\%$ \\
\hline \multirow{3}{*}{ At 1 min } & $<8$ & 4 & 4.0 & 13 & 13.0 & 17 & 8.5 \\
\hline & $\geq 8$ & 96 & 96.0 & 87 & 87.0 & 183 & 91.5 \\
\hline & Mean & $7.76 \pm 0.69$ & & $7.94 \pm 0.44$ & & $7.85 \pm 0.57$ & \\
\hline \multirow{2}{*}{ At 5 min } & $<8$ & 0 & - & 2 & 2.0 & 2 & 1.0 \\
\hline & $\geq 8$ & 100 & 100.0 & 98 & 98.0 & 198 & 99.0 \\
\hline Mean & & $8.99 \pm 1.05$ & & $9.21 \pm 0.98$ & & $9.10 \pm 1.02$ & \\
\hline
\end{tabular}

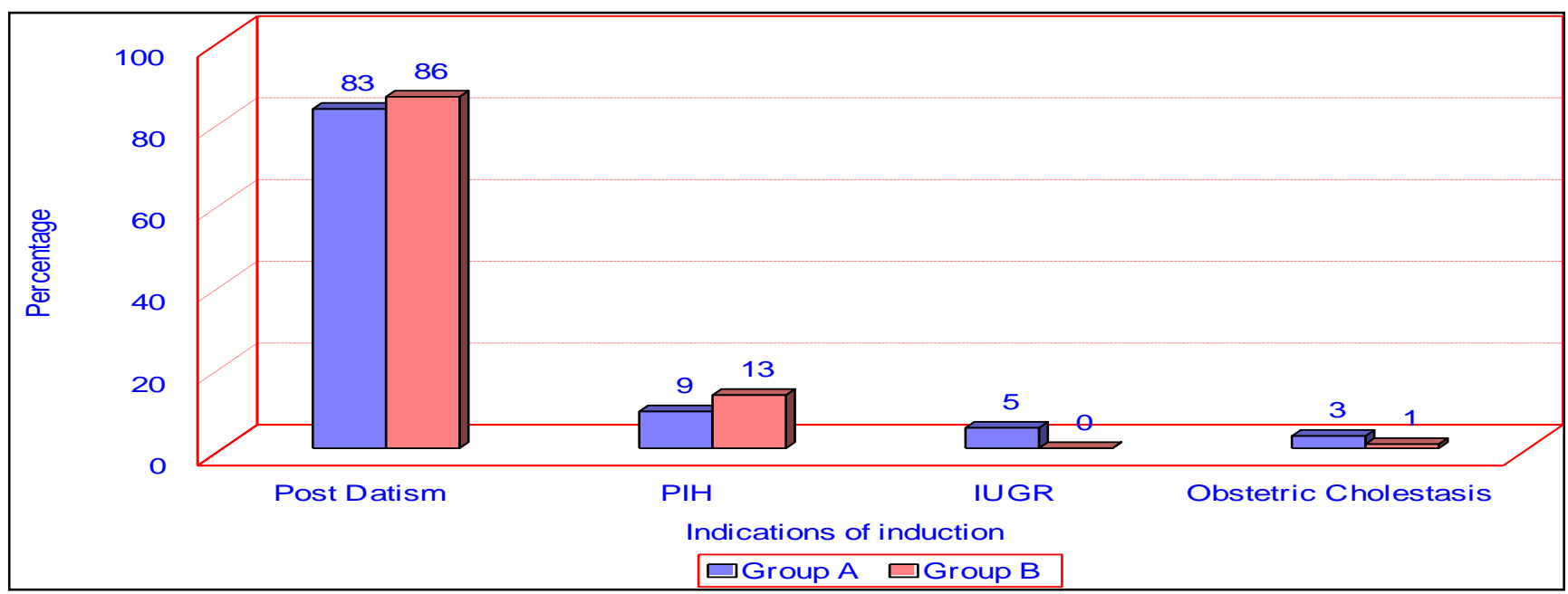

Figure 1: Distribution of cases according to the indications of induction.

\section{DISCUSSION}

\section{Age group}

In our study, out of total 200 cases, most common age group was 21-25 years in both the groups, in which group
A contained $44 \%$ and group B contained $45 \%$ cases. This was similar to study done by Maskharia et al which had $59.3 \%$ in group A and $65.2 \%$ in group B in age group of 21-25 years. ${ }^{8}$ Study done by Rao et al also comparable to our study which had $59.3 \%$ in group A and $65.2 \%$ in group $\mathrm{B}$ in the age group of $21-25$ years. ${ }^{9}$ 


\section{Parity}

In our study, out of total 200 cases, nulliparous and multiparous were $63.5 \%$ and $36.5 \%$ respectively. This study was comparable to study done by Gupta et al where $60 \%$ were primigravida and $40 \%$ were multigravida. ${ }^{10}$

This study also comparable to study done by Maskharia et al where $73 \%$ were primigravida, $27 \%$ were multigravida ${ }^{8}$ and also with the study done by Sheela Jayprakash et al where $67.5 \%$ women were nulliparous and $32.5 \%$ were multiparous. ${ }^{11}$

\section{Gestational age}

In our study, majority of cases had their gestational age between 37-38 weeks, where total $156(78 \%)$ cases were found. This was comparable with the study done by Jayprakash et al where $85 \%$ patients were of $>37$ weeks gestation. ${ }^{11}$

\section{Indication of induction}

In our study, out of 200 cases, 169, 22, 5 and 4 cases had their indication for induction as postdatism, PIH, IUGR and obstetric cholestasis respectively. Above data shows that most common indication for induction was postdatism $(84.5 \%)$ which was $83 \%$ and $86 \%$ in group A and group B respectively.

This was comparable with the study done by Rao et al where out of 100 cases, 76 had their indication for induction as postdatism with $75.9 \%$ in group A and $76.1 \%$ in group B. ${ }^{9}$

Study done by Mashkaria et al also comparable to our study where $62.5 \%$ were in group A and $75 \%$ were in group B had indication of postdatism. ${ }^{8}$

\section{Mode of delivery}

In our study, majority of cases (out of 200) i.e.; 155 $(77.5 \%)$ had vaginal delivery with $72 \%$ and $82 \%$ in single and double application group respectively and 45 (22.5\%) cases underwent cesarean section with $28 \%$ and $17 \%$ in single application and double application group respectively. This was comparable to the study done by Khichar et al where $73 \%$ and $80 \%$ cases delivered vaginally and $27 \%$ and $20 \%$ had LSCS in single application and double application group respectively. ${ }^{12}$

Study done by Gupta et al was also comparable to our study where $87.6 \%$ and $84 \%$ cases delivered vaginally and $12.3 \%$ and $16 \%$ had LSCS in single application group and double application group respectively. ${ }^{10}$

Our study was also comparable to study done by Raza et al where success rate in terms of vaginal delivery was $82 \% .{ }^{13}$
Study done by Deshmukh et al was also comparable to our study with incidence of vaginal delivery and LSCS was $74.28 \%$ and $25.71 \%$ respectively. ${ }^{14}$

Success rate in terms of vaginal delivery was $81 \%$ in study done by George et al which was also comparable to our study. 15

\section{Indications of LSCS}

In our study, out of 200 cases, 45 cases underwent cesarean section, main indication for LSCS (total 30 cases) was NPOL and failed induction in both the groups (66.7\%). NPOL and failed induction cases were higher in group A (23/28) compared to group B (7/17). FD and meconium with FD cases were higher in group B $(2 / 17,7 / 17)$ compared to group A $(2 / 28,3 / 28)$ respectively. There was only a single case of placental abruption which was in group B.

These results were comparable to the study done by Parate et al where no. of failed induction cases were more in single application group (2/8) compared to no failed induction in double application group. ${ }^{16}$

This study was also comparable to study done by Jayaprakash et al in which out of total 80 patients, 6 patients required LSCS, main indication of LSCS was failed induction (4/6) and other indication was fetal distress $(2 / 6){ }^{11}$

\section{Maternal complications}

In our study, maternal complications were slightly higher in group B. GIT symptoms (nausea and vomiting) were found in $5 \%$ vs $11 \%$ in single vs double application group. PPH found in $1 \%$ vs $2 \%$ in single v/s double application group. Hyperstimulation was in $2 \%$ cases in double application group only.

This study was comparable to study done by Khichar et al where GIT symptoms (nausea and vomiting) were found in $8 \%$ vs $11 \%$ in single vs double application group. PPH found in $3 \%$ vs $5 \%$ in single vs double application group. Hyperstimulation was in $2 \%$ vs $4 \%$ in single v/s double application group. ${ }^{12}$

\section{Apgar score}

In our study, out of 200 neonates, $8.5 \%$ neonates had their Apgar score $<8$ at $1 \mathrm{~min}$ and $1 \%$ neonates had their Apgar score $<8$ at $5 \mathrm{~min}$. No. of neonates having Apgar score $<8$ at 1 minute and 5 minute were slightly higher in group B, all 4 neonates in group A, which were having Apgar score $<8$ at 1 min improved to Apgar score $\geq 8$ at 5 min while in group B, 11 out of 13 neonates improved their Apgar score to $\geq 8$ at $5 \mathrm{~min}$, remaining 2 neonates had their Apgar score $<8$ at 5 min. Mean Apgar score at 1 minute in group A was 7.76 and in group B it was 7.94 and at 5 min mean APGAR score was 8.99 in group A and 9.21 in group B. 
This study was comparable to study done by Rao et al in which total about 3\% of newborns had their Apgar score $<7.9$

These results were also comparable to study done by Deshmukh et al in which mean Apgar score at 1 min was 7 and at 5 min was $9 .{ }^{14}$

\section{CONCLUSION}

Though further studies are mandatory to reach sound conclusions, available data suggests that intracervical application of PGE2 gel $0.5 \mathrm{mg}$ is an effective, safe and acceptable method for induction of labour in women with unfavourable cervix.

Double times application of ddinoprostone gel resulted in improved Bishop score, facilitates the process of induction, increased number of successful inductions, shortened application delivery interval and decreased cesarean section rate compared to single application. There was slight increase in maternal and fetal complications with double times application.

This study concluded that double time application should be used cautiously in appropriately selected cases.

\section{Funding: No funding sources}

Conflict of interest: None declared

Ethical approval: The study was approved by the Institutional Ethics Committee

\section{REFERENCES}

1. American College of Obstetricians and Gynecologists. Induction of labor. Practice bulletin No. 10. Washington, DC: ACOG; 1999.

2. Edwards RK, Richards DS. Pre-induction cervical assessment. Clin Obstet Gynecol. 2000;43:440-6.

3. Calder AA. Pharmacological management of the unripe cervix in the human. In: Naftolin F, Stubblefied PG, eds. Dilatation if uterine cervix. Lipincott; 1979: 317-333.

4. Prins RP, Bolton RN, Mark C 3rd, Neilson DR, Watson $\mathrm{P}$. Cervical ripening with intravaginal prostaglandin E2 gel. Obstet Gynecol. 1983;61(4):459-62.

5. Bishop EH. Pelvic Scoring For Elective Induction. Obstet Gynecol. 1964;24:266-8.
6. Mainprize T, Nimrod C, Dodd G, Persaud D. Clinical utility of multiple-dose administration of prostaglandin E2 gel. Am J Obstet Gynecol. 1987;156(2):341-3.

7. Panel P, Bascou V, Meeus JB, Magnin G. Maturation cervicale par applications itératives de gel de prostaglandines E2. Cervical maturation by repeated applications of prostaglandin E2 gel. 186 cases. J Gynecol Obstet Biol Reprod. 1997;26(4):386-94.

8. Mashkaria A, Shah SR, Mehta AV, Panchal PP, Mashkaria A. A comparative study of single versus repeat instillation of intravaginal prostaglandin E2 gel for induction of labour. Int $\mathrm{J}$ Reprod Contracept Obstet Gynecol. 2020; 9(11):4482-5.

9. Ramana MV, Fathima NMG. A comparative study of single versus multiple instillations of intravaginal PGE2 gel for induction of labour. Indian J Obstet Gynecol Res. 2019;6(3):282-7.

10. Gupta S, Kuntal N, Gupta VK. Maternal and fetal outcomes with the use of prostaglandins E2 as a cervical ripening agent for induction of labor. Int $\mathbf{J}$ Reprod Contracept Obstet Gynecol. 2020;9:44-7.

11. Jayaprakash S, Muralidhar L, Venkatesh S. Intracervical PGE2 gel for induction of labor in patients with prelabour rupture of membranes with unfavourable cervix after 34 weeks period of gestation. Int J Reprod Contracept Obstet Gynecol. 2016;5(5):1418-22.

12. Yadav R, Khichar MC. Application of dinoprostone gel single time verses double time and compare maternal and fetale outcome. Int J Inov App Res. 2019;(8):14.

13. Raza F, Majeed S. Intracervical PGE2 gel for cervical ripening and induction of labor. Pak J Med Sci. 2008; 24(2):241-5.

14. Deshmukh S, Jungari ML, Sharma U. Use of PG-32 gel for cervical ripening in labor induction. Int J Curr Res Rev. 2020;12(14):110-3.

15. George M, George SM. Effect of Cerviprime on Cervical Ripening and Induction of Labor. J Eval Med Dental Sci. 2015;4(18): 3162-8.

16. Parate S, Fidvi J. A comparative study of single and double dose of intracervical Prostaglandin E2 gel for cervical ripening. Int J Med Res Rev 2015;3(5):4849.

Cite this article as: Khajotia S, Gupta M, Khichar MC, Sharma M, Choudhary K. Comparative study of single versus double time application of dinoprostone E2 gel on the induction of labor in term pregnancy and it's fetomaternal outcomes. Int J Reprod Contracept Obstet Gynecol 2021;10:3186-91. 